\begin{tabular}{|l|l|l}
\hline & $\begin{array}{l}\text { Proceedings of the } \\
\text { Informing Science }+\end{array}$ & $\begin{array}{l}\text { An Official Publication } \\
\text { of the Informing Science Institute } \\
\text { InformingScience.org }\end{array}$ \\
\hline
\end{tabular}

June 30 - July 4 2019, Jerusalem, Israel

\title{
AdDRESSING THE CHALlENGE OF GUIDING OUR STUDENTS ON HOW TO DEAL WITH FAKE NEWS
}

Val Hooper*

Victoria University of Wellington,

val.hooper@vuw.ac.nz

Wellington, New Zealand

\begin{abstract}
Aim/Purpose In the face of the onslaught of fake news, we aim to address the challenge of how we, as academics, can guide our students to be able to critically assess and evaluate information.

Background Fake news has assumed alarming proportions and is a challenge to academia, organizations, causes and governments. How can our students be prepared to deal with this challenge?

Methodology Development of guidelines based on a literature review of multiple literatures.

Contribution A set of guidelines is presented, which can be used by academics and students in their determination of which is valid and truthful information and which is fake.

Findings A set of guidelines in which the core aspects of information and fake news communication as discussed. They are: fake news; social media; and the receiver's motivation; expectations; attitudes, biases, predispositions and brand loyalty; media engagement; and reference groups.
\end{abstract}

Recommendations The guidelines will help students deal with the phenomenon of fake news.

for Practitioners

Recommendations for Researchers

This research shows how communication theory can be used to address fake news. It also demonstrates a multi-disciplinary approach.

Impact on Society

Greater caution and discernment regarding information will be instilled into the minds of our students as future leaders of our economies and society.

Accepting Editor: Eli Cohen | Received: January 16, 2019 | Revised: February 24, 2019 |

Accepted: February 25, 2019.

Cite as: Hooper, V. (2019). Addressing the challenge of guiding our students on how to deal with fake news.

Proceedings of the Informing Science and Information Technology Education Conference, Jerusalem, Israel, pp. 21-32. Santa

Rosa, CA: Informing Science Institute. https://doi.org/10.28945/4341

(CC BY-NC 4.0) This article is licensed to you under a Creative Commons Attribution-NonCommercial 4.0 International License. When you copy and redistribute this paper in full or in part, you need to provide proper attribution to it to ensure that others can later locate this work (and to ensure that others do not accuse you of plagiarism). You may (and we encourage you to) adapt, remix, transform, and build upon the material for any non-commercial purposes. This license does not permit you to use this material for commercial purposes. 
Future Research Qualitative and quantitative expansion and testing of the validity of the findings; further testing of the impact of age, gender, culture and discipline studied on the influential factors proposed.

Keywords fake news, social media, communication theory, the receiver

\section{INTRODUCTION}

Many universities publicize their aim of ensuring that their graduates possess certain attributes. Among those attributes frequently noted are the ability to approach information critically, analyze it carefully and form sound, well-grounded decisions based on a careful and well-rounded consideration of relevant information. Victoria University of Wellington, for instance, notes that it prepares its graduates to be scholars who:

- have a specialized understanding of their chosen field(s) of study

- exhibit well-developed skills in critical and creative thinking

- communicate complex ideas effectively and accurately in a range of contexts

- demonstrate intellectual autonomy through independence of thought, openness to ideas and information and a capacity to manage their own learning

- demonstrate intellectual integrity and understand the ethics of scholarship (Victoria University of Wellington, 2019).

Given these aims and the plethora of information sources with which students are currently bombarded, the challenge for academics is how to guide the students to assess the information available, and actively offered, to them, and select that which most accurately reflects the truth. This is assuming that the pursuit of truth forms the basis of the academic endeavor.

While it used to be the case that forty and even thirty years ago, our access to information was relatively limited, the appearance of the Internet and the World Wide Web in 1993, plus the emergence of online social media, spearheaded by Facebook in 2004, has provided us with a deluge of information from a multitude of sources. Instead of authorship being limited to those whom "trustworthy/trusted" publishers and the mass media deemed credible, nowadays, every individual with access to the Internet is a potential author, and the credibility of such authors is no longer as unquestionable as in the past. Plus, the truth has taken on various forms such as post-truths, alternative facts and fake news, all of which have been identified as biased, skewed and even untruthful information. Yet the irony of the old maxim of, "if it's in print or communicated via the mass media, it must be correct" persists, and currently includes the online social media.

We are truly in the information age. However, while the main challenge of the age towards the end of the last century was seen to be how to deal with the mass of information on any one topic, more recently the challenge has shifted towards sifting the wheat from the chaff and having to decide on which of the information is true or valid, and which not. This is where the notion of fake news comes into play.

Fake news is deliberate misinformation or hoaxes spread via the traditional and online media with the intention of harming a person or entities, and/or gaining either financially or politically (Hunt, 2016; Leonhardt \& Thompson, 2017; Merriam-Webster, 2017; Schlesinger, 2017). Fake news flows along the same media channels as, and parallel with, "legitimate" news or information. Not only have social media greatly facilitated the flow of information but they have also been the conduits of huge amounts of fake news. In fact, more fake news stories have been shared on Facebook than any other mainstream medium (Silverman, 2016).

How then is the student to judge which information to believe and which not? Does it imply that we, as educators, have an even more important and responsible task of ensuring that the need for critical assessment of information is inculcated into our students? 
In addressing the challenge, we posit that it is ultimately the receiver of the information who makes the critical decision as to whether that information is valid and trustworthy or whether it is fake news. The receiver is thus the focus of this paper. Social media have greatly facilitated communication processes and the flow of information. Communication theory provides a suitable lens and basis for addressing the problem, and in the following sections, its relevance is demonstrated and the main components are explored. In addition, the core concepts of fake news and social media are examined. Our discussion then focusses on ways in which we, as academics, can guide our students to be as discerning as possible in their decisions of which information to trust and which to discard as fake. Indications for future research are provided.

\section{THEORETICAL BACKGROUND}

Communication theory broadly holds that the communication process consists of a number of core elements: the source/sender, the message, the channel or medium, and the receiver/destination (Shannon \& Weaver, 1948). The process involves a series of encryptions and decryptions and takes place against the background of noise (Chitty, Luck, Barker, Valos \& Shimp, 2015). The message is the focal element and can contain ideas, notions, facts and imaginings. The source of the message is the compiler of the message, and this can consist of an individual or a group such as in the case of an organization or government. The sender and the source are usually one and the same although not necessarily so. The sender encrypts the message into such formats as print, audio or film/video and sends it to a specific receiver or receivers, or to an anonymous group of receivers as in the case of mass media. The sender also chooses the medium or media along which to send the message. This can range from simple face-to-face word of mouth communication, to messages sent via a range of media such as the post, carrier pigeon, smoke signals, telegraph signals to via e-mail and social media. They can include specific one-to-one or one-to-a-few messages in which case the post, carrier pigeon or e-mail and certain social media, such as Facebook would be used. They can also include the mass media such as TV, radio, film outdoor advertisements, mobile advertisements and certain social media, such as Twitter. Obviously the choice of medium will depend on who the target receiver(s) is/are. The receiver receives the message, decrypts it, and then either acts upon it, commits it to memory, or simply discards it. Sometimes that action will only take place at some stage in the distant future. The whole process can end there, especially if the message was a one-way message such as in the case of mass media which do not require a reply, although they often require a responsive action such as purchasing a good or rallying to a cause. Alternatively, the process can continue with a feedback loop from the receiver to the sender/source in which the receiver responds to the ideas and notions sent by the sender. The background noise against which the communication process plays out can consist of competing messages or distracting ones, the topic of which might be more appealing than the main message (Chitty, Luck, Barker, Valos \& Shimp, 2015).

\section{RESEARCH METHOD}

In order to gain a good understanding of how fake news can influence our students, a literature review was conducted into three main areas: fake news (as the content of the message), social media (as the medium) and the receiver. Three different literature review strategies were selected for the data collection. For fake news, because it is a relatively understudied phenomenon in the academic literature, and because it is being addressed by many disciplines, from marketing to sociology, to media studies, to communications, to law and strategic studies, a scoping approach was adopted. Accordingly, breadth rather than depth was sought to ascertain the scope of the impact of fake news. Although, the historical precedents were examined, the current phenomenon, as it is facilitated by social media was the focus. Additionally, because of the recency of the phenomenon in its current social media-facilitated form, popular publications and newsfeeds were also relied upon. Social media as, facilitated by the Internet, is similarly a relatively new phenomenon, although with a larger and older coverage in the more academic literature than fake news and with a more limited multidisciplinary appeal - to sociology, media studies, communications, psychology, information systems, 
education and marketing. This facilitated a thorough collection of data especially around the core aspects of the phenomenon. The receiver stems from communications theory, and influences on the receiver's behaviour or consumption of fake news stems from consumer behaviour theory. Both are well-established disciplines, and the level to which they were applied in this research was at the more basic, core principles level. Consequently, the literature review in this regard was guided in the direction of foundational literature.

\section{FINDINGS}

The results of the literature review are presented according to the core concepts of fake news, social media and the receiver.

\section{FAKE NEWS}

The notion of fake news was initially introduced to the world by US President, Donald Trump, when he branded the reporting of $\mathrm{CNN}$ as fake news. Frustrated at not having his whole story or message reported, and instead having selected sections relayed in the media, Trump felt that they did not present the full picture and consequently declared that $\mathrm{CNN}$ was reporting incorrectly and skewing the meaning and emphasis of what he had said (Slack, 2017). He took this even further and started to brand any report, statement or opinion that did not accord with his sentiment or viewpoint as fake. Ironically, Trump has also been seen to benefit from fake news. Fake news stories were reportedly "heavily tilted in favor of Donald Trump" in the 2016 US Presidential elections (Allcott \& Gentzkow, 2017).

In fact, fake news had been around for a very long time. Not necessarily called "fake news" misinformation or disinformation has been used for centuries to discredit individuals, organizations or countries. For instance, fake news led to the eventual suicide of Mark Anthony. Lord Haw-haw's proNazi broadcasts during World War II to Britain and the Allied troops, is another example of the propagation of misinformation to deceive a nation. Since the mid-nineteenth century the Germans have had the phenomenon of "luegenpresse" which pejoratively refers to misinformation, typically disseminated by certain media (Chandler, 2015).

Rather than Trump's particular interpretation of the concept, fake news may be regarded as "deliberate misinformation or hoaxes spread via the traditional print and broadcast news media or online social media which are compiled with the intent to mislead in order to damage an agency, entity, or person and/or gain financially or politically", (Hunt, 2016; Leonhardt \& Thompson, 2017; MerriamWebster, 2017; Schlesinger, 2017).

It is the intention to deceive for selfish gain that distinguishes fake news from other forms of untruths. For instance, certain types of misinformation may be classified as parodies or hoaxes, but these are not regarded as fake news because their intention is not to deceive for financial or political gain but rather to entertain (Hunt, 2016). In such instances, the revenue from ticket sales or publishers' payments are not seen as being derived from the news or information itself, but rather from the entertainment provided (Kirby, 2016).

Taking it a step further, marketers are often given to extreme exaggeration - and they will gain financially from goods or services thus marketed but we have come to expect grossly exaggerated claims as painting the idyllic picture to which we aspire, and which is more like a fantasy. For instance, the use of a toilet freshener might be portrayed as one's toilet being magically converted into a garden full of roses. We know that such a conversion will not take place, yet we happily tolerate, and even expect, such metaphorical promotion of the expected change.

One of the ways in which fake news is most prolifically spread is via social media. The happy marriage of these two phenomena has served to bring the dangers of fake news to prominence, so much so that in 2018 the World Economic Forum featured its control as a major agenda item (Timmons, 
2018). Helen Zille, prominent South African politician, has even been quoted as stating: "In today's post-truth era, social media regard facts as irrelevant. They have, sadly, become platforms of distortion and deception that enable lies to circumnavigate the globe several times before truth's alarm clock even rings" (Zille, 2019).

\section{SOCIAL MEDIA}

Social media are Web 2 applications, which are based on the Internet (Aichner \& Jacob, 2015). Although social media sprang to prominence with the launch of Facebook in 2004, they had been in existence since the times of Arpanet in 1970. However, it was the more personal aspect of Facebook which appealed to the individual and accounted for the huge uptake. Subsequent developments in social media have generally included a personal focus. The existence of the Internet as a platform for the dissemination of social media also greatly facilitated their spread. Although some social media act as mass media, social media typically differ from traditional mass media in terms of reach, frequency, interactivity, usability, immediacy, permanence and quality.

Social media are sometimes described as social networking sites (Boyd \& Ellison, 2007). As such they have been described as web-based services that allow individuals to: (1) construct a public or semipublic profile within a bounded system, (2) articulate a list of other users with whom they share a connection, and (3) view and traverse their list of connections and those made by others within the system. In other words, social media allow individuals to promote a certain identity, to manage their relationships, and to build new ones. It was this "public" display of friends which originally distinguished social media from other forms of online media (Boyd \& Ellison, 2007). In promoting their identity, individuals have the opportunity to present their ideal selves and this has given rise to no small amount of self-exaggeration (Ahn, 2011).

In building and maintaining relationships, various forms of social capital evolve, and it is developing social capital that is the ultimate goal of social networking and social media. There are two main types of social capital: bridging or bonding (Putnam, 2000). Bridging social capital reflects "weak ties" (Granovetter, 1973). These are loose ties between individuals who often come from different backgrounds. Such ties are evident in professional sites such as LinkedIn. Bonding social capital refers to strong ties such as those between family members and close friends (Zinnbauer, 2007). One of the main reasons for building such connections is the provision of emotional support (Ellison, Heino, \& Gibbs, 2006) and whereas bridging social capital provides limited emotional support (Atfield, Brahmbhatt, \& O’Toole, 2007; Ellison, Steinfeld, \& Lampe, 2007), bonding social capital provides stronger emotional and instrumental support, and nurtures characteristics such as trust (Appel et al., 2014). A third type of social capital, maintained social capital, has been identified by Ellison et al. (2007). This type refers to the maintenance of connections with previous social networks which may have been in danger of being lost after one or other of the members has physically moved far away from the network (Ellison et al., 2007).

While the underpinning of social media was initially to build social capital through personal interaction, the benefits of building "social" capital without interaction was quickly identified and is currently being used by business, organizations and countries. In such instances the definition of social capital as "the extent, nature, quality of social ties that individuals or communities can mobilize in conducting their affairs" (Zinnbauer, 2007, p. 16) holds broadly true. Superior to mass media in many ways, especially in terms of reach, frequency, interactability and immediacy (Agichtein, Castillo, Fonato, Gionis \& Mishne, 2008), social media can act as a mass media broadcaster or can facilitate interaction between individuals, communities and governments, such as in times of natural disasters. Political parties and terrorist groups have also been quick to climb on the social media bandwagon.

Social media are constantly evolving (Weller, 2015) and currently they can take the form of simple interpersonal online sites, blogs, microblogs, social bookmarking, virtual worlds and enterprise social networks, to name a few (Aichner \& Jacob, 2015). In addition, the creation of automated or semi- 
automated bots presents the impression that an individual might be communicating with the receiver. Chat bots and social bots mimic human interaction and create the impression of activity and preferences, thereby falsely influencing others. Even more canny and difficult to identify are cyborgs which are a combination of human and bot activity. Bots can also filter the flow of information to an individual by feeding them only information which coincides with their previous preferences. A filter bubble is thereby created which limits the individual's exposure to other "conflicting" information and their potential to be influenced by it (Burkhardt, 2017). This is akin to Trump's notion of fake news as that which does not convey the full story.

\section{THE RECEIVER}

Ultimately the receiver makes the decision as to whether or not certain information is fake or not. In expanding upon the receiver, the fact that we need to focus on our students' susceptibility to fake news, frequent reference will be made to students. There are a number of factors that influence the receiver in their decisions. These are their motivation; their attitudes, biases, predispositions, and brand loyalty; their expectations; their media engagement; and their reference groups.

\section{Motivation}

The springboard of information seeking and use is the motivation or the purpose for which the information is to be used or consumed (Fullerton, 2013). Is it simply for the sake of curiosity, wanting to know what is going on in the world, wanting to understand certain phenomena, wanting guidance on most appropriate courses of action, wanting to learn how to do something, or is it simply for entertainment? Basically, information seeking and use can be divided into two categories: the need for hard, accurate facts; and the need for entertainment. A cross between the two would be the need to learn the opinions of certain sources. Usually those sources would have to be credible, although often it's simply for amusement or entertainment that opinions are sought. Sadly, for many the latter is the case with the US President, Donald Trump. Frequently his communications are so outrageous or unbelievable that his message is treated more as entertainment than hard fact or truth. The problem for students is, though, that it's difficult to differentiate between the truth and what is fake, and in many cases they are forced to rely on some mechanism of indicating the credibility of the source to determine the veracity and validity of the message.

In the example above, one would imagine that the President of the US would be honorable and not lie or fabricate information, or even twist it. However, Trump's frequent branding of information from certain sources, such as CNN whom many regard as highly credible, as fake news, has called Trump's statements into question by many.

Many have thus come to regard Trump's communication as entertainment rather than hard facts or truth. Entertainment is there to delight and amuse us, to evoke extreme emotional reactions, as well as making us think more deeply on specific matters. In such situations, we do not expect the truth. Rather, people are attracted to gossip, rumor, the salacious, scandal, innuendo, and the unlikely. People are thrilled by the shocking and horrendous and revel in each detail. Furthermore, the more shocking the information, the longer it remains in the memory - and it does so, whether it is correct or not (Burkhardt, 2017).

\section{Expectations}

Linked to the motivation to consume information is our set of expectations (Santos \& Boote, 2003). These expectations apply not only to the information or message that we will be receiving but also to the expected behaviour on the part of the source/sender and the medium.

Using the example of Donald Trump, at the outset of his term we had expectations of him that, as US President, he would uphold the principles of truth and honor. Information emanating from him was assumed to be accurate and truthful. However, as time has passed, more and more evidence has 
emerged that has indicated that this is not always the case (note the Russian involvement in the last US Presidential election) so that now many have come to take his communications with a grain of salt. In other words, we half-expect a measure of fakeness in his communications.

We also hold certain expectations of the media. Stemming from pre-Internet times, whatever was in print or in "black and white", be it books, magazines or newspapers, was regarded as the Gospel. Only those sceptics who had been (mis-)quoted or written about in the media doubted the sense of this view. The same held for the audio and audio-visual media such as radio and TV. This belief in the absolute truthfulness of the information produced by the mass media has been transferred, to a very large extent, to the information conveyed over the Internet. This definitely applies to certain social media, especially those such as Wikipedia, and search engines like Google. These two, in particular, have become household preferences as information sources - almost a modern replacement of the encyclopedia and the go-to favorites of most students. Lecturers are hard pressed to guide their students into questioning the validity and accuracy of what is reported in these media, and to not believing the information conveyed by them blindly.

Another expectation in our modern information seeking and consumption, is that of convenience (Willman-Iivarinen, 2017). Time is precious and it seems that the more information that is available, the more we are pressed to select out the most fitting for our purpose, the most comprehensive, and the most accurate. Often the latter criterion suffers at the hands of the former two. Accustomed to immediate satisfaction in our consumption of most things, we seek that same sort of satisfaction with our information searches. For students nowadays, information that is easily accessible, such as Wikipedia, takes preference over even the most user friendly online databases. And while Wikipedia and Google present some very sound, accurate information, other social media and search engines and not nearly so discerning.

In addition, there is the common use of algorithms amongst search engines, in particular, to filter information so that only the information that accords with that of one's last searches, is presented to the viewer - in other words, presenting them with fake news.

One further aspect of expectations is our willing suspension of disbelief. We have learnt to ignore our disbelief in certain situations and of certain phenomena, and willingly accept the information that is presented as if it were true. For instance, many marketing advertisements depict highly unlikely situations, such as groups of women falling at the feet of a man who uses a certain deodorant; or a celebrity 80-year old woman who is known to have had many facelifts, promoting a certain skin cream which seems to make her look as though she has a flawless, wrinkle-free skin. We know that the advertisements present untruths yet we suspend our disbelief in the interests of our desire to "believe" the virtually impossible ideal. This is akin to our motivation of information seeking.

\section{Attitudes, biases, predispositions and brand loyalty}

Closely associated with motivation and expectations are our attitudes, biases, predispositions and brand loyalty. Attitudes are the total of both positive and negative beliefs that an individual holds about an action or object. The positive and negative beliefs outweigh each other so that the larger the number of positive or negative beliefs, the more positive or negative our attitude (Fishbein \& Ajzen, 1975).

Biases and predispositions represent pre-determined attitudes and feelings about an object or action. These will exercise an underlying influence on which information is consumed and which is ignored or discounted. Often these biases and predispositions seem irrational or else they are so deeply ingrained culturally that there is no swaying of such perspectives. Culture exists at a deeper level than attitudes and is extremely difficult to change whereas attitudes can be changed by changing the number and content of positive or negative beliefs. (Kotler \& Keller, 2015). 
Attitudes, biases and predispositions will thus predetermine which information the receiver will accept as true or valid and use. Information that does not agree with the receiver's attitudes, biases and predispositions will simply be discarded at best, or else branded as fake at worst.

Although the discussion so far has focused on the message content, the receiver's attitudes, biases and predispositions also apply to the sender, the source and the medium. In addition, brand loyalty to certain celebrity individuals, to organizational sources and media also play an important influential role. Such brand loyalty will often serve to overlook occasional inaccuracies or faults in information communicated. Thus, fake news received via a medium such as Facebook to which many participants are extremely brand loyal, stand a high chance of being accepted. It is important to note that brand loyalty is strongly underpinned by trust - a trusting attitude, and even a trust bias (Kotler \& Keller, 2015).

\section{Medium engagement}

The extent to which the receiver engages with the same medium and different media will exert a significant influence on the way in which they assess and use the information received via those channels. It is well known that users of social media typically use a variety such as Facebook, Twitter, LinkedIn, Instagram - all for slightly different purposes. In the use of this variety, they are exposed to different perspectives and views on any given topic. They are thus able to triangulate the information, comparing one message with another. This advantage allows them to gain a better balanced view and to make better-informed decisions.

Unfortunately, though, users tend to follow fashions and preferences in terms of which social media they prefer so that younger users prefer Twitter and Instagram while older users prefer Facebook, and professional users LinkedIn. Marketers and organizations tend to go with the medium that most closely targets the same market as them, whereas certain countries have even banned the use of some social media, such as China banning Facebook. This is particularly relevant to students coming from China and even those coming from countries like Iraq.

One should also not forget the issue of convenience and time pressures (Willman-Iivarinen, 2017). Many receivers employ heuristics, or mental short cuts, to determine which news is truthful and which is fake. Much of this short-cutting is determined by the trust the receiver places in the source/sender and the medium. This is very evident in student's preferred use of Wikipedia. That trust will also be heightened through frequent use of the medium by a receiver. The greater the amount of engagement, the greater the number of truthful or trustworthy messages they receive, the greater the complacency, and the greater the chances of them being duped by fake news.

\section{Reference groups}

Reference groups play a significant role in influencing an individual in which information to regard as true and valid and which as fake. Reference groups typically consist of family members, friends, colleagues and interest groups with whom one identifies. The latter can include organizations with whose culture one assimilates, political groups, hobby groups or even countries with their national cultures. Depending on the individual's age and stage in life so certain reference groups assume more or less prominence and influence (Fishbein \& Ajzen, 1975). For instance, friends and peer groups are extremely important to teenagers and continue to be so, often until an individual marries or matures in the work environment. In this next stage, the spouse's influence assumes prominence or that of work colleagues and bosses. Esteemed individuals or celebrities frequently serve as reference points and often exert an undue amount of influence - especially on topics not within their area of expertise. Thus, when Donald Trump indicated that $\mathrm{CNN}$ was reporting fake news, many who regarded him with high esteem and used him as a reference point, decided that CNN was indeed communicating fake news. Interestingly, the older an individual becomes, the less they tend to rely on the opinions of others and the less they refer to reference groups. 


\section{DISCUSSION}

All things being equal, it is assumed that the tertiary education students of today will generally rise to become the leaders of our future economies, societies and countries. It is thus vital that their decision making in terms of which information they will believe and act upon, is as thoroughly examined for veracity as possible, and is not fake news. It thus behooves us, as academics, to instill certain guidelines into our students for how best to do this. Such training and reminding should follow them throughout their tertiary education careers.

Given the findings of the current research, it is evident that there are a number of areas to which academics need to alert students to be aware of where and how they can fall into the fake news trap.

Firstly, students need to be aware that not all information and news is equal in terms of accuracy, currency and comprehensiveness. They need to be clear on the purpose for which the information is being disseminated - it is to reflect the news, current research facts, opinions, or is it for entertainment (Hunt, 2016)? Is there a call to action, such as with political movements, natural disasters, and marketing sales? To what extent are we required to suspend our disbelief, such as in marketing advertisements, or in parodies, cartoons or hoaxes such as those on April Fool's Day? The student needs to question all these and recognize the purpose of both the source/sender and the message (Kotler \& Keller, 2015).

Secondly, students need to question the possible biases of their preferred media, especially social media. The ultimate purpose of social media is to facilitate the building of a support network but students need to recognize their potential to herd and follow the masses/fashion in using only one medium, without gaining the perspectives offered by other media (Kotler \& Keller, 2015). The importance of triangulation lies at the heart of academic enquiry. Students should also be alerted to bots and cyborgs and the dangers of simply believing blindly. In addition, they should be aware of how many sites and search engines filter the information that one receives so that one is not always exposed to the full range of available information (Burkhardt, 2017).

Thirdly, the student, as the receiver of the information or news, needs to examine their motivation for engaging with a medium - is it to ascertain the latest, most accurate information, is it to learn of the opinions or other or is it to be entertained (Fullerton, 2013)? They need to be sure that their motivation aligns with the purpose for which the message was compiled and sent, and the aims of the source/sender. Students also need to bear in mind the natural tendency to be drawn to the sensational and shocking. The sometimes relatively dull good news should also receive due regard.

Another consideration for students is their expectations (Santos \& Boote, 2003). In many instances, expectations go hand in hand with the purpose of our information search but they also are also indicative of the expected or presumed response. When the information does not accord with this presumed response we often discard it. Furthermore, expectations go hand in hand with our desire for immediate satisfaction, and we thus tend to limit our searches to the media to which we are accustomed and trust without necessarily questioning their trustworthiness.

Alongside expectations, students need to be aware of their attitudes, biases and predispositions which might limit their openness to seeking out information that might not be as conveniently accessed, and which might disagree with previously held beliefs (Fishbein \& Ajzen, 1975). In other words, information that will take them outside their comfort zone. Furthermore, for similar reasons, they need to pay attention to their brand loyalties (Kotler \& Keller, 2015).

Fourthly, students need to recognize why they chose to engage with certain media, especially social media, and question those reasons. To what extent were those choices limited by fashion, herding behaviour, convenience, time pressures, and complacency from frequent use (Willman-Iivarinen, 2017)? They need to question whether their choices have led to a limitation of the information to which they are allowing themselves to be exposed (Fishbein \& Ajzen, 1975). 
Lastly, students will benefit from an awareness of the extent to which they are influenced by their reference groups (Fishbein \& Ajzen, 1975). We all have reference groups but the group think of these groups shouldn't result in us not allowing ourselves to seek information which differs from the views of the group. Reference groups will influence the credibility given to all components of the communication process. As already noted, special caution needs to be exercised with regard to bots, cyborgs and filtering of certain social media and search engines (Burkhardt, 2017).

\section{CONCLUSION}

This paper set out to address the challenge of how we, as academics, can best guide our students in an age of fake news, on ways and means of seeking out and distinguishing valid, true and trustworthy information, and deciding which information they should discard. How can we ensure that the need for critical assessment of information is inculcated into our students?

Using communication theory as the basis, we analyzed the existing literature to come up with a set of guidelines on what students should be aware of in their quest. These guidelines focused on the content and purpose of the message, and of the medium, and the various relevant influences on the receiver of the information, in this case the student. These influences include their motivation, their expectations, their attitudes, biases, predispositions, and their brand loyalty. The extent of media engagement is another influential factor, as is the effect of reference groups on the student's information use behaviour.

Further research in this area should include empirical examination of these influential factors - first qualitatively, then quantitatively. The effects of moderating factors such as age, gender, cultural background, and discipline should also be studied because indications are that they would be significant.

\section{REFERENCES}

Agichtein, E., Castillo, C., Fonato, D., Gionis, A., \& Mishne, G. (2008). Finding high-quality content in social media. Proceedings of the 2008 International Conference on Web Search and Data Mining (pp. 183-193). New York, NY, USA: ACM. https://doi.org/10.1145/1341531.1341557

Ahn, J. (2011). The effect of social network sites on adolescents' social and academic development: Current theories and controversies. Journal of the American Society for Information Science and Technology, 62(8), 14351445. https://doi.org/10.1002/asi.21540

Aichner, T., \& Jacob, F. (2015). Measuring the degree of corporate social media use. International Journal of Market Research, 57(2), 257-275. https://doi.org/10.2501/IJMR-2015-018

Allcott, H., \& Gentzkow, M. (2017). Social media and Fake News on the 2016 election. Journal of Economic Perspectives, 31(2), 211-236. https://doi.org/10.1257/jep.31.2.211

Appel, L., Dadlani, P., Dwyer, M., Hampton, K., Kitze, V., Matni, Z. A., Moore, P., \& Teodoro, R. (2015). Testing the validity of social capital measures in the study of information and communication technologies. Information, Communication \& Society, 17(4), 398-416. https://doi.org/10.1080/1369118X.2014.884612

Atfield, G., Brahmbhatt, K., \& O’Toole, T. (2007, 01 September). Refugees' experiences of integration. Refugee Council and University of Birmingham. Retrieved May 25, 2018 from https://www.bl.uk/britishlibrary/ /media/bl/global/social-welfare/pdfs/non-secure/r/e/f/refugeesexperiences-of-integration-001.pdf

Boyd, D, \& Ellison, N. (2007). Social network sites: Definitions, history and scholarship. Journal of ComputerMediated Communication, 13(1), 210-230. https://doi.org/10.1111/j.1083-6101.2007.00393.x

Burkhardt, J. M. (2017). Combating fake news in the digital age. Chicago, Illinois, USA: American Library Association. Retrieved from https://www.journals.ala.org/index.php/ltr/issue/viewFile/662/423

Chandler, A. (2015, 14 January). The "worst" German word of the year. The Atlantic. Retrieved from https://www.theatlantic.com/international/archive/2015/01/the-worst-german-word-of-theyear $/ 384493 /$ 
Chitty, W., Luck, E., Barker, N., Valos, M., \& Shimp, T. A. (2015). Integrated marketing communications. Melbourne: Cengage Learning.

Ellison, N., Heino, R., \& Gibbs, J. (2006). Managing impressions online: Self-presentation process in the online dating environment. Journal of Computer-Mediated Communication, 11(2), 415-441. https://doi.org/10.1111/j.1083-6101.2006.00020.x

Ellison, N. B., Steinfield, C., \& Lampe, C. (2007). The benefits of Facebook "friends": Social capital and college students' use of online social network sites. Journal of Computer-Mediated Communication, 12(4), 1143-1168. https://doi.org/10.1111/j.1083-6101.2007.00367.x

Fishbein, M., \& Ajzen, S. (1975). Belief, attitude, intention and behaviour: An introduction to theory and research. Boston, Massachusetts, USA: Addison-Wesley.

Fullerton, R. (2013). The birth of consumer behavior: Motivation research in the 1940s and 1950s. Journal of Historical Research in Marketing, 5(2), 212-222. https://doi.org/10.1108/17557501311316833

Granovetter, M. S. (1973). The strength of weak ties. American Journal of Sociology, 78(6), 1360-1380. https://doi.org/10.1086/225469

Hunt, E. (2016, 17 December). What is fake news? How to spot it and what you can do to stop it? The Guardian. Retrieved August 16, 2018 from https://www.theguardian.com/media/2016/dec/18/what-is-fakenews-pizzagate

Kirby, E. J. (2016, 5 December). The city getting rich from fake news. BBC News. Retrieved August 16, 2018 from https://www.bbc.com/news/magazine-38168281

Kotler, P. T., \& Keller, K. L. (2015). Marketing management (15 $5^{\text {th }}$ ed.). New York: Pearson.

Leonhardt, D., \& Thompson, S. A. (2017, 23 June). Trump's lies. New York Times. Retrieved August 16, 2018 from https://www.nytimes.com/interactive/2017/06/23/opinion/trumps-lies.html

Merriam-Webster (2017, 23 March). The real story of 'fake news'. Retrieved from https://www.merriamwebster.com/words-at-play/the-real-story-of-fake-news

Putnam, R. D. (2000). Bowling alone: America's declining social capital. In Culture and Politics (pp. 223-234). New York: Palgrave Macmillan. https://doi.org/10.1145/358916.361990

Santos, J., \& Boote, J. (2003). A theoretical exploration and model of consumer expectations, post-purchase affective states and affective behaviour. Journal of Consumer Behaviour, 3(2), 142-156. https://doi.org/10.1002/cb.129

Schlesinger, R. (2017, 14 April). Fake News in Reality. US News and World Report, Online. Retrieved February 26, 2018 from https://www.usnews.com/opinion/thomas-jefferson-street/articles/2017-04-14/what-is-fakenews-maybe-not-what-you-think

Shannon, C. E., \& Weaver, W. (1948). A mathematical theory of communication. The Bell System Technical Journal, 27(4), 379-423, 623-656. https://doi.org/10.1002/j.1538-7305.1948.tb00917.x

Silverman, C. (2016, 16 November). This analysis shows how viral fake election news stories outperformed real news on Facebook. BuzzFeed News. Retrieved from https://www.buzzfeednews.com/article/craigsilverman/viral-fake-election-news-outperformed-real-newson-facebook

Slack, D. (2017, 11 Januray). Trump to CNN: You are fake news. USA Today. Retrieved January 31, 2018 from https://www.usatoday.com/story/news/politics/onpolitics/2017/01/11/trump-cnn-pressconference/96447880/

Timmons, H. (2018). Google executives are floating a plan to fight fake news on Facebook and Twitter. Quart\%: Retrieved February 26, 2018 from https://qz.com/1195872/google-facebook-twitter-fake-news-chrome/

Victoria University of Wellington. (2019). Graduate profile. Retrieved from https://www.victoria.ac.nz/learningteaching/partnership/graduate-profile

Weller, K. (2015). Accepting the challenges of social media research. Online Information Review, 39(3), 281-289. https://doi.org/10.1108/OIR-03-2015-0069 
Willman-Iivarinen, A. (2017). The future of consumer decision making. European Journal of Futures Research, 5(1), 1-12. https://doi.org/10.1007/s40309-017-0125-5

Zille, H. (2019, 7 January). From the inside: Tales from the tablet - the truth will out. The Daily Maverick. Retrieved January 102019 from https://www.dailymaverick.co.za/opinionista/2019-01-07-from-the-insidetale-of-the-tablets-the-truth-will-out/?utm source=Ince FirstThing

Zinnbauer, D. (2007). What can social capital and ICT do for inclusion? Institute for Prospective Technological Studies (IPTS). Luxembourg: JRC European Commission. Retrieved from ftp://ftp.jrc.es/pub/EURdoc/eur22673en.pdf

\section{BIOGRAPHY}

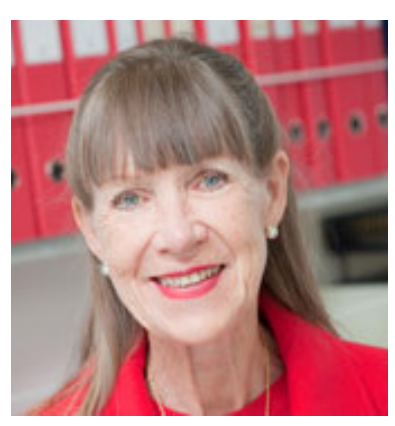

Associate Professor Val Hooper is currently the Head of the School of Marketing and International Business at Victoria University of Wellington in New Zealand. She was previously the Head of the School of Information Management. These positions are indicative of her crossdisciplinary background in Marketing and IT. Val has published widely and holds senior editorial positions on a number of journals. Her research interests include the dark side of the Internet and especially the aberrant behaviour induced by the Internet environment, be it on social media, security compliance, or the impact on education. 